\title{
Relato de Experiência de Estágio em Psicologia Escolar: Grupo com Pais
}

\author{
Relato de Experiencia de Práctica en Psicología Escolar: Grupo con Padres
}

\author{
Report of Stage Experience in School Psychology: Group with Parents
}

\author{
Renata Garcia Fisch \\ Faculdade Meridional (IMED), Passo Fundo-RS/Brasil \\ ORCID: 0000-0003-0464-0286 \\ E-mail: renata-fisch@hotmail.com
}

Naiana Dapieve Patias

Faculdade Meridional (IMED), Passo Fundo-RS/Brasil ORCID: 0000-0001-9285-9602

E-mail: naipatias@ hotmail.com

\begin{abstract}
Resumo
O trabalho com os pais pode ser uma forma de intervenção do psicólogo escolar. O intuito é contribuir para a melhora na relação família e escola e, desta forma, auxiliar no comportamento e no desempenho escolar dos alunos. Este trabalho tem como objetivo descrever e discutir uma intervenção em grupo com pais de alunos de ensino fundamental realizado durante o Estágio Básico I e II em Psicologia. Foram realizados cinco encontros com pais/cuidadores em espaço cedido pela escola. Os mesmos ocorreram com frequência quinzenal e duração aproximada de uma hora e meia cada encontro. Nos encontros foram trabalhados temas demandados pela escola e pelos pais, a saber: objetivos da família e da escola; educação dos filhos e bullying. Os pais não tiveram assiduidade nos encontros. No entanto, o grupo possibilitou um início de aproximação entre família e escola.
\end{abstract}

Palavras-chaves: Família; Escola; Psicologia escolar.

\section{Resumen}

El trabajo con los padres puede ser una forma de intervención del psicólogo escolar. El objetivo es contribuir a la mejora de la relación de familia y la escuela y por lo tanto ayudar en el comportamiento y el rendimiento escolar de los estudiantes. Este trabajo tiene como objetivo describir y analizar una intervención grupal con los padres/cuidadores de los estudiantes de escuelas primarias realizadas durante la Fundación Etapa I y II en Psicología. Cinco reuniones se llevaron a cabo en el espacio proporcionado por la escuela. Los mismos ocurrieron con frecuencia quincenal y duración aproximada de una hora y media cada encuentro. En las reuniones que se trabajaron temas exigidos por las escuelas y los padres, a saber: metas de la familia y la escuela; la educación de los niños y la intimidación. Los padres no tenían la asistencia a las reuniones. Sin embargo, el grupo posibilitó un inicio de acercamiento entre familia y escuela.

\begin{abstract}
Working with parents can be a form of school psychologist intervention. The aim is to contribute to the improvement in family and school relationship and thus help to improve the academic performance of students. This paper aims to describe to discuss a group intervention with parents/caregivers of elementary school students conducted during the Basic Stage I and II in Psychology. Five meetings were held in a space provided by the school. They occurred with fortnightly frequency and with an approximate duration of one and a half hours each. The themes worked in each meeting were demanded by schools and parents, namely: the family and the school goals; children's education and bullying. The parents did not attend all the meetings. However, the group allowed an early rapprochement between family and school.
\end{abstract}

Keywords: Family; School; School Psychology.

Palabras clave: Familia; Colegio; Psicología escolar. 


\section{Introdução}

\section{A Psicologia Escolar/Educacional} busca, por meio de várias ferramentas teóricas e técnicas, atuar de maneira crítica na escola, considerando singularidades, mas também a produção social das queixas escolares diante da complexidade dessas instituições e de sua construção histórica, social, cultural e política. Por meio de uma atuação a nível institucional, o/a Psicólogo/a Escolar analisa o contexto e suas demandas propondo intervenções em nível coletivo (Marinho-Araujo, 2014) por meio do trabalho envolvendo todos os atores escolares (professores, alunos, pais ou responsáveis e funcionários) (Conselho Federal de Psicologia, [CFP], 2013). Desta forma, são produzidas novas formas de olhar as queixas escolares que são quase que, predominantemente, relacionadas aos alunos e suas famílias (Labadessa \& Lima, 2017).

Reconhecida como uma especialidade pelo Conselho Federal de Psicologia (CFP, 2007) por meio da resolução 013/2007, nem sempre a Psicologia Escolar/Educacional teve, em sua prática, um modelo crítico de intervir na realidade escolar. De uma maneira acrítica e excludente, a Psicologia Escolar/Educacional teve seu início marcado pela realização de avaliação e diagnósticos de alunos para a escola regular. $\mathrm{O}$ modelo clínico, individualizante e excludente permaneceu por muitos anos, sendo que ainda mantêm resquícios em práticas de alguns psicólogos que atuam na educação (Barbosa \& De Souza, 2012; Barbosa \& Marinho Araujo, 2010; Guzzo, Mezzalira, Moreira, Tizzei, \& Silva Neto, 2010; MarinhoAraujo, 2014) constatando-se, frequentemente, uma desarticulação entre teoria e prática (Aquino, Lins, Cavalcanti, \& Gomes, 2015; Medeiros \& Aquino, 2011).

$\mathrm{Na}$ prática, observa-se o trabalho voltado quase que exclusivamente, no(s) "aluno(s) problema(s)" ou em suas famílias, individualizando demandas que podem e devem ser tratadas de forma sistêmica. Esta individualização pode ser uma prática do psicólogo que cede aos pedidos da escola, a qual possui uma visão clínica do fazer psi na escola (Aquino et al., 2015; Guzzo et al., 2010; Marinho-Araújo, 2014; 2016; Marinho-Araújo \& Almeida, 2014; Oliveira-Menegotto \& Fontoura, 2015). Ao atender a demanda de maneira singular, o/a psicólogo/a perde a oportunidade de trabalhar de forma institucional e grupal, incluindo os diversos "atores" do contexto escolar que estão implicados na queixa (Marinho-Araújo, 2014; 2016).

Pensando desta forma, o trabalho em grupo pode ser uma boa ferramenta para intervenções na escola. Especificamente o trabalho com pais e/ou cuidadores torna-se essencial na medida em que a família é um importante contexto de influência na vida de crianças e adolescentes. Ainda, a família pode contribuir ou prejudicar as implicações do(s) aluno(s) na escola. Sabe-se, por exemplo, que uma boa parceria entre família e escola pode ser preditora de saúde, melhorar comportamentos e desempenho acadêmico dos alunos (Fantinato \& Cia, 2011; Maia \& Dantas, 2017; SaraivaJunges \& Wagner, 2016).

No entanto, nem sempre família e escola possuem um relacionamento saudável capaz de contribuir para que crianças e adolescentes aprendam e possam gostar da escola. Uma revisão sistemática sobre a relação família e escola demonstrou que podem ocorrer desentendimentos entre esses microssistemas, sendo que nem sempre família e escola compartilham dos mesmos valores e opiniões. Ocorre que a escola não entende a ótica das famílias, podendo afirmar seu domínio de maior conhecimento sobre os dos pais e/ou cuidadores. Por sua vez, estes podem entender que seu saber não é importante e, desta forma, deixar de se envolver nas atividades escolares do(s) filho(a/s) (Saraiva-Junges \& Wagner, 2016).

De fato, muitas vezes, as famílias acabam delegando à escola inúmeras tarefas. A escola, por outro lado, acaba por chamar a família apenas quando "as coisas vão mal", comunicando-se com ela por meio de bilhetes ou de reuniões de pais (Saraiva-Junges \& Wagner, 2016). Estas formas de comunicação 
não contribuem para uma boa relação entre os microssistemas. Por outro lado, algumas atitudes podem contribuir para que família e escola sejam parceira na educação de crianças e adolescentes, tais como: acolhimento das famílias desde o primeiro contato com a escola; conhecer alunos e famílias antes de ocorrerem dificuldades; procurar favorecer $\mathrm{o}$ comparecimento dos pais ou cuidadores na escola; dar feedback que estimule a reflexão; chamar a família regularmente na escola não apenas para informar problemas, mas para falar das potencialidades, entre outras (Maia \& Dantas, 2017).

Outro aspecto importante que diz respeito a relação família refere-se à educação de crianças e adolescentes. A família, considerada o primeiro socializador das crianças, tem um importante papel nas regras e normas que atribui a elas por meio das estratégias educativas. Já a escola é o segundo importante contexto de socialização, sendo que nela crianças e adolescentes têm oportunidades de vivenciarem outras regras (Dessen \& Polônia, 2007; Fantinato \& Cia, 2011). Desta forma, a escola acaba sendo uma "vitrine" em que comportamentos aprendidos em ambiente familiar são manifestados no âmbito escolar.

Desta forma, a importância das intervenções entre família e escola advém da possibilidade de fomentar espaços para que essas instituições dialoguem acerca dos seus papéis e funções na aprendizagem, desenvolvimento e proteção das crianças e adolescentes (Guzzo, Mezzalira, Weber, Sant'Ana, \& Silva, 2018). Além disso, a escassez de estudos relacionados às intervenções da psicologia escolar sobre família e escola também indica a importância da discussão de intervenções realizadas (Albuquerque \& Aquino, 2018).

Sendo assim, este artigo tem como objetivo descrever e discutir uma intervenção em grupo com pais/cuidadores de alunos de ensino fundamental, a qual foi realizada durante o Estágio Básico I e II em Psicologia de uma Instituição de Ensino Superior. Esse estágio é o primeiro contato do graduando com a prática do psicólogo e tem o intuito de observar demandas do contexto em que é realizado e propor estratégias de intervenção, segundo demandas observadas.

\section{Método}

A escola em que foi realizada a intervenção é pública e situa-se na cidade de Passo Fundo, no Estado do Sul do Brasil. A instituição atende alunos de ensino fundamental que se caracterizam por famílias em situação de vulnerabilidade social. O estágio Básico I e II é componente curricular obrigatório na graduação em Psicologia, sendo o primeiro estágio, com duração de dois semestres letivos (cerca de 8 meses), iniciando no sexto e finalizando no sétimo semestre da graduação em psicologia. A estagiária em psicologia deve realizar 105 horas no local de estágio, o que contabiliza, em média, cinco horas semanais na escola e um turno de supervisão acadêmica de estágio, em grupo. Em supervisão, a estagiária relata as observações realizadas, bem como a/s atividade/s desenvolvidas, destacando os principais aspectos para que o docente, supervisor de estágio, possa discutir os aspectos abordados pensando em melhores estratégias de intervenção. Várias intervenções foram realizadas como, por exemplo, grupos com crianças, observações sistemáticas, escuta de pais e alunos, organização de confraternizações junto com a escola, participação em reuniões de professores. No entanto, no presente artigo, será descrita a intervenção realizada junto aos pais e/cuidadores.

Especificamente, acerca desse relato, após a inserção da estagiária na escola, foram realizadas observações, conversas com a equipe diretiva, principalmente com a orientadora educacional, e com professores dos terceiros e quartos anos do ensino fundamental, os quais indicaram a necessidade de alguma intervenção com os alunos das referidas turmas. Tais alunos apresentavam dificuldades comportamentais, desrespeito com os professores e brigas frequentes entre os alunos, incluindo episódios de agressão física. O intuito da escola era individualizar a intervenção, 
indicando que a problemática poderia referir-se a problemas comportamentais relacionados ao Transtorno Desafiador Opositivo (TDO), Transtorno de Conduta e/ou Transtorno de Déficit de Atenção e Hiperatividade (TDAH).

No entanto, em conversas com os pais e outros cuidadores dos referidos alunos, a estagiária de psicologia e também a orientadora educacional, perceberam que muitas destas dificuldades poderiam estar associadas aos comportamentos dos próprios pais/cuidadores na educação dos filhos, seja pela falta de limites ou pelo uso de práticas educativas inadequadas, como a punição física. Essas dificuldades eram presentes nas falas dos pais e de outros cuidadores (como avôs) que diziam "não sei mais o que fazer com ele(a)" (sic), "eu surro, ponho de castigo e não adianta" (sic). Desta forma, pode-se (re) significar a queixa escolar e ampliá-la de forma a considerar não apenas o aluno e sua família, mas também a relação da escola com a mesma.

Por exemplo, uma importante situação ocorrida na escola e que demonstrou o quanto o comportamento dos pais influencia comportamentos que se apresentam na escola foi quando duas adolescentes se agrediram fisicamente. Uma das mães, ao ser chamada na escola, afirmou que a estratégia utilizada para punir a filha foi deixá-la nua e bater forte, da cabeça aos pés, até ficar com marcas pelo corpo. Estas falas expressam dificuldades de encontrar estratégias eficazes para educar os filhos e uma crença de que a forma adequada de educar é bater, aspecto difundido histórica e socialmente (Azevedo \& Guerra, 2010; Santini \& Williams, 2011). Além disso, a atitude materna indica que a consequência para $o$ comportamento violento da adolescente foi incongruente, visto que a violência também foi propagada pela mãe. Isso impossibilita a "quebra" de padrão educativo e comportamental.

Cabe destacar que, durante o período de estágio, foram realizadas notificações ao Conselho Tutelar mais próximo da escola em função da violação de direitos das crianças e adolescentes, cumprindo com o artigo 13 do
Estatuto da Criança e do Adolescente (ECA) "Art. 13. Os casos de suspeita ou confirmação de castigo físico, de tratamento cruel ou degradante e de maus-tratos contra criança ou adolescente serão obrigatoriamente comunicados ao Conselho Tutelar da respectiva localidade, sem prejuízo de outras providências legais" (Lei $\left.n^{\circ} 8.069,1990\right)$. A notificação foi sempre realizada pela escola, principal responsável, com o auxílio da estagiária.

Desta maneira, foi pensada e construída uma intervenção para pais e outros cuidadores dos alunos das turmas (terceiros e quartos anos) com o intuito de refletir sobre os comportamentos dos filhos e sobre as melhores estratégias educativas diante de tais comportamentos. Além disso, o intuito foi aproximar família e escola para que ambas pudessem pensar em estratégias eficazes para educar. O grupo também foi aberto para a família extensa (tios, avôs, etc) e/ou outras pessoas que fazem o cuidado da criança ou adolescente. $\mathrm{O}$ intuito da intervenção não era culpabilizar os pais, nem os ensinar como educar os filhos, mas propor um espaço para falarem de suas dificuldades e encontrarem, junto com a escola e outros pais ou cuidadores, estratégias mais eficazes de educar os filhos. Nos casos em que foram, de fato, observados comportamentos que remetiam a quadros de transtornos mentais da infância e adolescência, foram realizados encaminhamentos para avaliações psicológicas.

Foram realizados cinco encontros, com frequência quinzenal e com duração de cerca uma hora e meia cada, nas dependências da escola. O grupo era aberto, ou seja, se algum pai, mãe ou cuidador não tivesse participado do primeiro encontro, poderia, se assim desejasse, participar do próximo. Participaram, dos grupos, de 3 a 13 pais/cuidadores. Nos grupos, foram tratados temas relacionados aos comportamentos e estratégias educativas, bem como comportamentos comuns que ocorrem na escola e como os pais poderiam auxiliar escola e vice e versa. Foram utilizados slides, material impresso e vídeos para a realização dos grupos, além de livre discussão entre os membros do 
grupo, a estagiária de psicologia e a orientadora educacional da escola.

\section{Resultados e discussão \\ Primeiro encontro: o contrato e a apresentação do objetivo do grupo}

O primeiro encontro foi realizado com o objetivo de apresentar o projeto aos pais e demais cuidadores, verificando se a demanda analisada pela estagiária era, de fato, a necessidade da família, para além da necessidade da escola. Além disso, nesse encontro, foram estabelecidas as regras do grupo bem como dias e horários de funcionamento. $\mathrm{O}$ projeto foi construído pela estagiária, supervisionada pela segunda autora do artigo e também discutido com a Orientadora Educacional (OE) da escola. No projeto, haviam assuntos a serem tratados nos encontros com os pais, de acordo com demandas observadas pela estagiária e também em conversar informais com a $\mathrm{OE} e$ pais/cuidadores.

No primeiro encontro participaram 13 pais/cuidadores. O objetivo era de que eles pudessem dar sua opinião sobre suas necessidades e se o projeto atenderia as mesmas. Durante o encontro, os pais/cuidadores foram fazendo relatos das suas dificuldades e de suas mudanças ao longo da vida, como: "Meus pais me bateram muito, então, eu não bato no meu neto hoje" (sic), ou "eu tento colocar de castigo, bater, brigar, mas depois, meu filho faz tudo errado novamente, então, não sei o que fazer" (sic).

Enquanto a estagiária, juntamente com a orientadora educacional, apresentava os temas, os pais/cuidadores foram relatando a necessidade de auxílio diante das dificuldades em casa com os seus filhos, sendo que muitas famílias se constituem como monoparentais femininas ou possuíam pais ausentes, o que produz uma sobrecarga emocional e também financeira. A falta de apoio da escola também foi comum nas falas dos pais "estava esperando isso há muito tempo, pois ninguém ajuda os pais" (sic). Muitos falaram que, em diversas situações, não sabem qual a melhor maneira de agir, reforçando o que fora anteriormente percebido pelos professores e pela estagiária.

Neste encontro, os pais/cuidadores puderam expressar suas dificuldades, anseios e necessidades. A estagiária deixou claro que ali era um espaço para conversarem, trocarem ideias e que a principal regra do grupo era o do não julgamento. Também falou que poderiam convidar outros pais e cuidadores, bem como outras pessoas da família. Os pais/cuidadores que participaram do encontro ressaltaram a importância e necessidade daquele espaço para poderem dialogar com outros pais e com a escola. Ao final do encontro, foram realizadas combinações para os próximos encontros.

\section{Segundo encontro: papel da escola e da família}

No segundo encontro, apenas três pais participaram. Neste dia, foi conversado sobre as responsabilidades dos pais/cuidadores e responsabilidades da escola, com o objetivo de refletir sobre qual o papel de cada instituição e o que cada um pode fazer para contribuir para o aprendizado e comportamento dos alunos. Foi abordada a importância de pais e escola saberem suas responsabilidades e terem uma comunicação clara, sendo aliados no processo. Naquele dia, os pais puderam expressar seus descontentamentos com a escola e esta, por meio da orientadora educacional, pode refletir, junto com os pais, sobre as dificuldades de comunicação e como poderiam manejar essa questão. Uma das principais reclamações, por parte dos pais, foi a de que a escola não possibilitava espaços de diálogo, como o que estava sendo desenvolvido, demonstrando a importância do mesmo ser desenvolvido.

Além disso, foi realizada uma dramatização de uma situação ocorrida na escola com o objetivo dos pais/cuidadores vivenciarem a situação e pensarem em estratégias mais adequadas de resolução de conflitos. A situação dramatizada foi a do conflito entre uma mãe e uma professora, na qual a mãe coloca a responsabilidade da perda dos lápis do seu filho na professora. Já 
professora agride a mãe verbalmente. A dramatização foi realizada pela estagiária e orientadora educacional.

Os pais puderam pensar em ambas as partes, dando dicas para solucionar ou pensar a resolução do problema de forma assertiva como, por exemplo, a mãe ouvindo a versão da professora e esta escutando a versão da mãe com tom de voz adequado. O mesmo foi realizado pensando para outras situações cotidianas.

\section{Terceiro encontro: as estratégias de educação de crianças e adolescentes}

No terceiro encontro, foi abordado, de forma específica, as estratégias que os pais utilizam para educar os filhos, refletindo sobre quais seriam adequadas ou não no sentido de auxiliar no desenvolvimento infantil, de acordo com estudos atuais. Neste encontro participaram oito pais. Foi aberta discussão para falar sobre estratégias educativas que não contribuem para o desenvolvimento $\mathrm{e}$ comportamentos adequados dos filhos e que acabam por se refletir na escola, como a violência verbal e física. Alguns pais acreditavam que tais estratégias eram corretas e outros sabiam que não eram adequadas, mas não entendiam como poderiam fazer diferente. Os pais lembraram e discutiram que, por diversas vezes, utilizam estas estratégias como forma de educar os filhos, pois foram educados assim.

Outros pais puderam expressar crenças como: "mas só uma palmada não faz mal" (sic), "eu apanhei e sou uma pessoa do bem" (sic), "tem que dar uns tapas para aprender" (sic), "melhor apanhar de mim do que da policia depois" (sic). Todas essas falas foram discutidas entre estagiária, orientadora educacional e os pais, indicando a importância de buscar outras estratégias que auxiliem no desenvolvimento dos filhos. A estagiária pode fazer os pais/cuidadores refletirem sobre a educação atual e também sobre pesquisas que referem as consequências da punição física.
Ainda, foram trabalhadas algumas formas de resolver as dificuldades enfrentadas sem o uso da força física ou ameaça, como possibilidades, de acordo com o que cada cuidador acreditava que poderia ser útil na sua relação com seu(s) filho(s). Nesse momento, a estagiária conversou com os pais afirmando que não há "receitas", mas que cada um deve encontrar maneiras e estratégias que podem auxiliar, desde que não seja utilizada a violência como estratégia, pois ela produz danos para a criança e para a relação entre pais e filhos.

Alguns pais conseguiram auxiliar os demais pais, por meio de trocas sobre quais estratégias utilizam com seus próprios filhos, trazendo exemplos de situações e como as manejaram. Algumas estratégias que foram discutidas em contraposição à violência, foram: elogiar as atitudes adequadas dos filhos e conversar para que as combinações sejam claras entre eles (cuidadores e escola). Ao final do encontro, os pais pediram que as discussões fossem continuadas no encontro posterior.

\section{Quarto encontro: educação de crianças e adolescentes e os seus efeitos}

No quarto encontro, continuou-se com o tema educação dos filhos, devido ao pedido dos pais no encontro anterior. Desta forma, neste encontro foi tratado, de forma específica, sobre "limites". Este momento foi muito importante, pois a maior parte dos pais ou cuidadores relataram muita dificuldade em "dar limites" (sic) aos seus filhos, e os que conseguiam tomar essa atitude era por meio da violência verbal e física.

Durante o encontro foram pensadas estratégias, em conjunto com os pais, sobre formas mais adequadas de "dar limites aos filhos". Constatou-se que a maior parte dos pais era permissivo em relação aos comportamentos dos filhos. Por outro lado, outros relataram situações que acreditavam ser uma forma de dar limites "eu bato no meu filho, coloco de castigo e mesmo assim não resolve" (sic). Ao ouvir os relatos dos pais, a estagiária conversou sobre a diferença entre "dar limites" e bater, discutindo 
sobre os efeitos da agressão e formas adequadas de dar limites como, por exemplo, conversando, sendo coerente nas regras, etc. Os pais puderam trocar novas experiências, sendo a estagiária, um mediadora nas trocas de informações.

\section{Quinto encontro: a violência que aparece na escola-Bullying}

No quinto e último encontro, sete pais participaram. O tema "bullying" foi trabalhado, pois esse envolvia muitas situações com os alunos na escola e, por esta razão, os pais eram solicitados a comparecer. Quando eram chamados, os pais apresentavam discursos que se contrapunham às necessidades da escola, seja por falta de informação, seja pela maneira com que acreditavam que os conflitos deviam ser resolvidos. Estes discursos demonstram que os pais acabam por auxiliar na manutenção do bullying, comportamento repetitivo e intencional que causa sofrimento aos envolvidos (vítima, agressor e espectadores/testemunhas) (Bandeira \& Hutz, 2012; Brito \& Oliveira, 2013; Moura, Cruz, \& Quevedo, 2011; Pigozi \& Machado, 2015).

Os pais demonstravam crenças comuns a respeito do bullying: "isso é brincadeira de criança” (sic), "não pode levar desaforo pra casa" (sic). O tema foi discutido com o intuito de dar continuidade às discussões sobre as estratégias educativas parentais e quais aspectos podem interferir na utilização das estratégias como, por exemplo, as crenças que os pais ou cuidadores possuem acerca da violência e sua naturalização, como demonstrado em algumas falas dos pais a respeito do bullying.

Dessa forma, esse encontro teve como objetivo conscientizar sobre a problemática do bullying, comum na escola, e sobre como os pais poderiam auxiliar a escolar a enfrentar o problema. Nesse encontro, os pais relataram as dificuldades relacionadas ao bullying $\mathrm{e}$ as dificuldades no que diz respeito a resolução da problemática. Um dos pais falou:
O meu filho me falou que não queria ir pra escola devido a um colega chamar ele de gordo, e eu disse que ele não era, que o que o colega falava era bobagem (sic).

Já outro pai ensinava o filho vítima de bullying a agir de maneira inadequada "eu já avisei o meu filho, se alguém falar alguma coisa para você, tem que bater, não pode deixar $\operatorname{assim}(\operatorname{sic})$.

Após as discussões sobre situações ocorridas, a estagiária tentou auxiliar os pais a identificar se os filhos estão sofrendo ou praticando bullying e quais são as ações a serem tomadas a partir disso como, por exemplo: avisar o(a) professor(a) e pedir ajuda. Além disso, foram discutidas práticas que não são adequadas como, por exemplo, ensinar o filho(a) a revidar; ignorar a situação, entre outras. A orientadora educacional também pode refletir acerca do papel da escola no enfrentamento do bullying. Ao final do encontro, foi realizada uma avaliação sobre os mesmos e uma confraternização.

\section{Um panorama geral sobre o grupo com pais}

O intuito da intervenção foi possibilitar espaço de reflexão para que pais e escola pudessem, juntos, discutir aspectos relacionados, principalmente, à educação de crianças e adolescentes. No geral, percebeu-se que os pais que participaram dos grupos começaram a questionar-se sobre a maneira com que tinham sido educados pelos pais e como estavam fazendo agora, ao serem pais ou cuidadores. A maior parte deles concordou que aplica as mesmas estratégias educativas adotadas pelos seus pais, ou seja, apesar de muitos perceberem que a maneira como foram educados talvez não tenha sido a melhor, continuam repetindo padrões de educação. As reflexões sempre buscaram entender a perspectiva dos pais, sem julgamento. As mesmas sempre foram com o intuito de questionamento e troca de informações entre os pais/cuidadores e estagiária. 
Ainda, no decorrer dos encontros, foi possível observar a ajuda mútua entre os pais que trocavam informações e experiências. No entanto, outros pais demonstravam receio em perceber a sua contribuição nas dificuldades relatadas pelo seu filho, sendo que atribuíam toda a responsabilidade aos filhos, o que tornou o processo de mudança um pouco mais difícil. Por outro lado, outros pais conseguiram observar atitudes que julgam inadequadas e que praticam com seus filhos, porém, relatavam a dificuldade da mudança. Este aspecto é importante, pois há vários fatores que influenciam a educação de crianças e adolescentes, sendo a forma como os pais foram educados, uma variável de grande influência. Ainda, o contexto social, econômico e cultural em que a família se desenvolve, a rede de apoio social e características dos pais (personalidade, uso de substância psicoativas, experiência de violência com seus próprios pais) como das crianças (temperamento infantil, idade, gênero, ordem de nascimento) também são aspectos importantes a serem considerados (Mondin, 2008; Patias, Siqueira, \& Dias, 2013).

Embora alguns pais possam ter dificuldades em reconhecer que suas estratégias educativas não são eficazes, pois são violação de direitos e prejudicam o desenvolvimento dos filhos, puderem ter um espaço de reflexão e escuta, sem julgamento, e uma maior aproximação com a escola que também pode refletir acerca de seu papel e da importância de estabelecer uma parceria com a família, aspecto já referenciado por autoras da psicologia escolar (Albuquerque \& Aquino, 2018; Guzzo et al., 2018).

No que diz respeito ao encontro em que o bullying foi discutido, percebeu-se a necessidade de intervir na escola como um todo, para as situações ocorridas, pois a fala de alguns pais demonstram que os filhos sofrem a vitimização, mas nem sempre a escola sabe ou faz algo. Os pais, por sua vez, nem sempre sabem qual a forma de proceder, ora considerando uma "brincadeira de criança", ora pedindo que o(a) filho(a) revide à situação. Nenhuma das estratégias é adequada. No entanto, a escola também deve estar preparada para agir em situações como essas, aspecto destacado por alguns estudos (Bandeira \& Hutz, 2012; Grossi \& Santos, 2011). O encontro foi importante para que escola e pais reconhecessem que deveriam atuar em conjunto para romper com a naturalização do bullying e o sofrimento de crianças e adolescentes diante das situações.

Outro aspecto importante de ser observado foi que, ao longo dos encontros, somente dois homens se fizeram presentes no grupo, sendo que participaram apenas de um encontro. Sobre isso, muitas mães fizeram o relato de que seus maridos não quiseram participar, pois atribuíam a elas o papel de ir até a escola sempre que necessário e, consequentemente, o papel exclusivo da mãe na educação dos filhos (Wagner, Predebon, Mosmann, \& Verza, 2005). Esse aspecto demonstra que muitas mulheres, além de trabalharem fora de casa, continuam com a responsabilidade pela educação dos filhos, estando sobrecarregadas. A participação dos pais e outros cuidadores é essencial, pois poderá contribuir com a diminuição da sobrecarga das mulheres, bem como, para que os cuidadores possam atuar de maneira coerente.

\section{Considerações finais}

Apesar de saber que os pais e/ou cuidadores necessitariam de um acompanhamento maior e de uma ajuda constante, foram extremamente válidos os cinco encontros, pois conseguiu-se perceber que apesar do curto tempo, existiu uma maior reflexão entre os cuidadores e também da escola, aspectos até então não pensados. Os conteúdos abordados nos encontros do grupo permitiram que a estagiária avaliasse, juntos com os pais, as melhores atitudes para uma relação mais saudável com seus filhos e, junto com os cuidadores e a orientadora educacional, como escola e família podem atuar em conjunto promovendo relações mais saudáveis. de relações mais saudáveis entre escola e família. Durante este processo, muitos relataram 
sentimentos positivos por estarem refletindo e conseguindo mudar algumas atitudes habituais.

Ao longo dos encontros realizados e após a sua finalização, alguns cuidadores foram fazendo relatos de suas reflexões em casa sobre os assuntos tratados nos encontros e assim conseguiram perceber o que de positivo faziam e quais atitudes poderiam melhorar. Além disso, os encontros permitiram uma maior aproximação entre escola e pais, fortalecendo os vínculos de ajuda mútua $\mathrm{e}$ corresponsabilidade, possibilitando que a presença dos pais seja constante, em forma de parceria com a escola e não apenas quando "algo não vai bem na escola".
Como limitações, destaca-se que a intervenção não foi avaliada por meio de nenhum instrumento para verificar mudanças nas estratégias educativas parentais ou na relação família e escola. Por outro lado, sugerese a continuidade deste tipo de intervenção da psicologia na escola para que mais cuidadores possam participar e outros temas possam ser tratados. Outro aspecto é o fato da orientadora educacional participar dos encontros que pode ser um aspecto facilitador para contribuir para a relação entre família e escola. No entanto, também pode ser um dificultador, podendo diminuir a participação dos pais por receio em falar.

\section{Referências}

Aquino, F., Lins, R., Cavalcante, L., \& Gomes, A. (2015). Concepções e práticas de psicólogos escolares junto a docentes de escolas públicas. Psicologia Escolar e Educacional, 19(1), 71-78. doi: 10.1590/2175-3539/2015/0191799

Albuquerquer, J. A., \& Aquino, F. S. B. (2018). Psicologia escolar e relação família-escola: Um levantamento da literatura. Psico-USF, 23(2), 307-318. doi: 10.1590/1413-82712018230210

Azevedo, M. A., \& Guerra, V. N. (2010) Mania de bater: A punição corporal doméstica de crianças e adolescentes no Brasil. São Paulo: Iglu.

Bandeira, C. de M., \& Hutz, C. S. (2012). Bullying: prevalência, implicações e diferenças entre os gêneros. Psicologia Escolar e Educacional, 16(1), 35-44. doi: 10.1590/S1413-85572012000100004

Barbosa, D. R., \& De Souza, M. P. R. (2012). Psicologia Educacional ou Escolar? Eis a questão. Psicologia Escolar e Educacional, 16(1), 163-173. doi: 10.1590/S1413$\underline{85572012000100018}$

Barbosa, R. M., \& Marinho-Araujo, C. M. (2010). Psicologia escolar no Brasil: Considerações e reflexões históricas. Estudos de Psicologia, 27(3), 393-402. doi: 10.1590/S0103-166X2010000300011
Brito, C., \& Oliveira, M. (2013). Bullying e autoestima em adolescentes de escolas públicas. Jornal de Pediatria, 89(6), 601607. doi: 10.1016/j.jped.2013.04.001

Conselho Federal de Psicologia [CFP]. (2007). Resolução $n^{\circ} 013$ de 2007. Institui a Consolidação das Resoluções relativas ao Título Profissional de Especialista em Psicologia e dispõe sobre normas e procedimentos para seu registro. Recuperado de https://site.cfp.org.br/wpcontent/uploads/2008/08/Resolucao_CFP_n x_013-2007.pdf

Conselho Federal de Psicologia. (2013). Referências técnicas para atuação de psicólogas(os) na educação básica.

Brasília: CFP. Recuperado de http://www.crpsc.org.br/ckfinder/userfiles/f iles/14_\%20Educação\%20Básica.pdf

Dessen, M. A., \& Polonia, A. C. (2007). A família e a escola como contextos de desenvolvimento humano. Paidéia, 17(36), 21-32. doi: $10.1590 / \mathrm{S} 0103-$ $\underline{863 X 2007000100003}$

Fantinato, A. C., \& Cia, F. (2011). Envolvimento parental, competência social e o desempenho acadêmico de escolares. Psicologia Argumento, 29(67), 499-511. Recuperado de https://periodicos.pucpr.br/index.php/psicol ogiaargumento/article/view/20401/19665 
Guzzo, R. S. L., Mezzalira, A. S. C., Moreira, A. P. G., Tizzei, R. P., \& Silva Neto, W. M. (2010). Psicologia e educação no Brasil: Uma visão da história e possibilidades nessa relação. Psicologia: Teoria e Pesquisa, 26, 131-141. doi: 10.1590/S0102-37722010000500012

Guzzo, R. S. L., Mezzalira, A. S. C., Weber, M. A. L., Sant'Ana, I. M., \& Silva, S. S. G. T. (2018). Psicologia escolar e família: importância da proximidade e diálogo. In V. L. T. Souza, F. S. B. Aquino, R. S. L. Guzzo. \& C. M. Marinho-Araujo (Orgs.), Psicologia Escolar Crítica: Atuações emancipatórias nas escolas públicas (pp. 142-162). Campinas: Alínea.

Grossi, P. K., \& Santos, A. M. (2009).

Desvendando o fenômeno bullying nas escolas públicas de Porto Alegre, RS, Brazil. Revista Portuguesa de Educação, 22(2), 249-267. Recuperado de http://www.scielo.mec.pt/scielo.php?script $=$ sci $\operatorname{arttext} \&$ pid $=$ S087191872009000200011\&lng $=p t \& t \operatorname{lng}=p t$

Labadessa, V. M., \& Lima, V. A. A. (2017). Queixa escolar: Repercussões na escola a partir do atendimento psicológico.

Psicologia Escolar e Educacional, 21(3), 369-377. doi: $\underline{10.1590 / 2175-}$

3539201702131116

Lei $n^{\circ}$ 8.069, de 13 de julho de 1990. Dispõe sobre o Estatuto da Criança e do Adolescente e dá outras providências. Recuperado de http://www.planalto.gov.br/ccivil_03/leis/LL $\underline{\text { 8069.htm }}$

Maia, D., \& Dantas, N. (2017). Família, escola e aprendizagem. In M. Rozek \& C. L. K. Domingues (Orgs.), As dificuldades de aprendizagem e o processo de escolarização (pp.125-141). Porto Alegre: EDIPUCRS.

Marinho-Araujo, C. M. (2014). Intervenção institucional: Ampliação crítica e política da atuação em Psicologia Escolar. In R. S. L. Guzzo (Org), Psicologia escolar: Desafios e bastidores da escola pública (pp.153-175). Campinas: Alínea.

Marinho-Araújo, C. M. (2016). Perspectiva histórico-cultural do desenvolvimento humano: Fundamentos para atuação em psicologia escolar. In M. V. Dazzani \& V. L. T. de Souza (Orgs.), Psicologia escolar crítica: Teoria e prática nos contextos educacionais (pp. 37-55). Campinas: Alínea.

Marinho-Araújo, C. M., \& Almeida, S. F. C. (2014). Psicologia escolar: construção e consolidação da identidade profissional $\left(3^{\mathrm{a}}\right.$ Ed.). Campinas: Alínea.

Medeiros, L. G., \& Aquino, F. S. B. (2011). Atuação do psicólogo escolar na rede pública de ensino: Concepções e práticas. Psicologia Argumento, 29(65), 227-236. Recuperado de https://periodicos.pucpr.br/index.php/psicol ogiaargumento/article/view/20377

Mondin, E. M. C. (2008). Práticas educativas parentais e seus efeitos na criação dos filhos. Psicologia Argumento, 26(54), 233244. Recuperado de https://periodicos.pucpr.br/index.php/psicol ogiaargumento/article/viewFile/19885/1918 $\underline{7}$

Moura, D., \& Cruz, A., \& Quevedo, L. (2011). Prevalência e características de escolares vítimas de bullying. Jornal de Pediatria, 87 (1), 19-23. doi: 10.1590/S0021-75572011000100004

Oliveira-Menegotto, L., \& Fontoura, G. P. (2015). Escola e psicologia: Uma história de encontros e desencontros. Psicologia Escolar e Educacional,19(2), 377-386. doi: 10.1590/2175-3539/2015/0192869

Patias, N. D., Siqueira, A. C., \& Dias, A. C. G. (2013). Práticas educativas e intervenção com pais: A educação como proteção ao desenvolvimento dos filhos. Mudanças Psicologia da Saúde, 21(1), 29-40. doi:10.15603/2176-1019/mud.v21n1p29-40

Pigozi, P. L., \& Machado, A. L. (2015).

Bullying na adolescência: Visão panorâmica no Brasil. Ciência \& Saúde Coletiva, 20(11), 3509-3522. doi: 10.1590/1413-812320152011.05292014

Santini, P.M. \&, Williams, L.C.A. (2011). Castigo corporal contra crianças: $\mathrm{O}$ que podemos fazer para mudar essa realidade? In C. V. B. B. Pessoa, C. E. Costa \& M. F. 
Benvenuti (Eds.), Comportamento em foco (pp. 603-612). São Paulo: ABPMC.

Saraiva-Jungues, L., \& Wagner, A. (2016). Os estudos sobre a relação família-escola no Brasil. Revista Educação (PUCRS), 39, 114-124. doi: $10.15448 / 1981-$ 2582.2016.s. 21333
Wagner, A., Predebon, J., Mosmann, C., \& Verza, F. (2005). Compartilhar tarefas? Papéis e funções de pai e mãe na família contemporânea. Psicologia: Teoria e Pesquisa, 21(2), 181-186. doi: $\underline{10.1590 / \mathrm{S} 0102-37722005000200008}$

\section{Dados sobre as autoras:}

- Renata Garcia Fisch: Psicóloga, Faculdade Meridional (IMED).

- Naiana Dapieve Patias: Psicóloga, Especialista em Psicologia Escolar (FATO), Doutora em Psicologia (UFRGS), Docente dos cursos de graduação e mestrado em Psicologia na Faculdade Meridional (IMED).

A submissão de originais para este periódico implica na transferência, pelos autores, dos direitos de publicação impressa e digital. Os direitos autorais para os artigos publicados são do autor, com direitos do periódico sobre a primeira publicação. Os autores somente poderão utilizar os mesmos resultados em outras publicações indicando claramente este periódico como o meio da publicação original. Em virtude de sermos um periódico de acesso aberto, permite-se o uso gratuito dos artigos em aplicações educacionais e científicas desde que citada a fonte conforme a licença CC-BY da Creative Commons. 